\title{
Cubic Octanuclear Ni(II) Clusters in Highly Porous Polypyrazolyl-Based Materials
}

\author{
Norberto Masciocchi, ${ }^{\dagger}$ Simona Galli, ${ }^{*, \dagger}$ Valentina Colombo, ${ }^{\dagger}$ Angelo Maspero, ${ }^{\dagger}$ Giovanni Palmisano, ${ }^{\dagger}$ \\ Behnam Seyyedi, ${ }^{\ddagger}$ Carlo Lamberti, ${ }^{\ddagger}$ and Silvia Bordiga ${ }^{*, \neq}$ \\ Dipartimento di Scienze Chimiche e Ambientali, Università dell'Insubria, via Valleggio 11, I-22100 Como, \\ Italy and Department of Chemistry IFM \& NIS Centre of Excellence, University of Turin,
} via Quarello 11, I-10135 Torino

Received April 6, 2010; E-mail: simona.galli@ uninsubria.it

Over the past two decades, many efforts have been devoted to devise hybrid three-dimensional porous systems, in which metallic nodes are linked by long organic spacers, ${ }^{1}$ aiming at the formation of thermally stable and chemically inert materials ${ }^{2}$ for gas storage, gas separation, and catalytic purposes. To this goal, polycarboxylates $^{3}$ and, later, polyazolates ${ }^{4}$ have been largely employed, reaching significant scientific and technological achievements, with some of the best performing materials being marketed by leading chemical companies. $^{5}$

The versatility of these systems can be traced back to the variety of the metallic nodes (either simple ions or polymetallic oxoclusters), of the organic linkers, of the different synthetic techniques, and to the possibility of generating polymorphic species depending on the reaction or on the environmental conditions. Altogether, thousands of species of this kind have appeared in the literature: ${ }^{6}$ while some have been serendipitously isolated, several highly performing materials were engineered using (poly)metallic nodes with specific geometric requirements, ${ }^{7}$ ligands of tailored coordination capacity, and, particularly, the highly fruitful isoreticular approach. ${ }^{8}$ In this respect, the polycarboxylate species of Yaghi ${ }^{9}$ and Férey, ${ }^{10}$ as well as the polyazolate materials reported by Long, ${ }^{11}$ are widely considered renowned cornerstones of this field.

In past years we have been interested in the coordination chemistry of homoleptic metal pyrazolates, imidazolates, and pyrimidinolates, ${ }^{12}$ which have demonstrated an extreme structural versatility, witnessed by the existence of cyclic oligomeric species, ${ }^{13}$ stretched $^{14}$ and helical ${ }^{15}$ 1D polymers, layered compounds, and dense, as well as porous, 3D frameworks. ${ }^{16}$ After shifting our interests toward polytopic nitrogen ligands containing several donor sites, ${ }^{17}$ we have eventually prepared two new bis-pyrazolyl species, 4,4'-bis(1H-pyrazol-4-yl)biphenyl, 1, $\mathrm{H}_{2}$ pbp, and 2,6-bis(1H-pyrazol-4-yl)pyrrolo[3,4-f]isoindole-1,3,5,7(2H,6H)-tetrone, $\mathrm{H}_{2}$ tet (Chart $1)$, in which the heterocycles are separated by long rigid spacers.

Chart 1. Molecular Drawings of Species 1 and 2

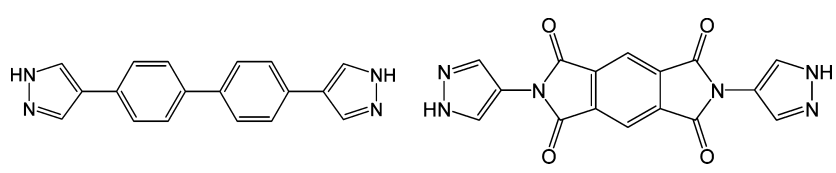

The preparation of $\mathbf{1}$ strictly followed the synthetic route reported by us $^{17}$ and others ${ }^{11,18}$ for the isolation of 4,4'-bis( $1 H$-pyrazol-4yl)benzene: 1 was recovered in analytically pure form starting from 1,1'-biphenyl-4,4'-bis(acetic acid), through the Vilsmeier-Haack reaction ${ }^{19}$ followed by heterocyclization with hydrazine, without

\footnotetext{
† Università dell'Insubria

University of Turin.
}

isolation of the $\beta$-dicarbonyl intermediate. In contrast, species $\mathbf{2}$ was prepared by reacting 4-aminopyrazole with pyromellitic anhydride in a one-pot reaction. These highly insoluble species could be recovered as polycrystalline materials, the structure of which was retrieved by X-ray powder diffraction (XRPD) data. ${ }^{20}$ Both of these rod-like molecules crystallize in the $P 2_{1} / c$ space group, within rather elongated cells, in which evident $\mathrm{N}-\mathrm{H} \cdots \mathrm{N}$ interactions among neighboring molecules generate corrugated twodimensional sheets of fishbone aspect, well separated from adjacent ones. Details of syntheses, spectroscopic properties, and structures are supplied in the Supporting Information (SI).

On reacting $\mathbf{1}$ and $\mathbf{2}$ with $\mathrm{Ni}(\mathrm{OAc})_{2} \cdot 4 \mathrm{H}_{2} \mathrm{O}$ in a variety of solvents, two polycrystalline derivatives, $\left[\mathrm{Ni}_{8}(\mathrm{OH})_{4}\left(\mathrm{OH}_{2}\right)_{2}(\mathrm{pbp})_{6}\right] \cdot \mathrm{nSolv}$ and $\left.\left[\mathrm{Ni}_{8}(\mathrm{OH})_{4}\left(\mathrm{OH}_{2}\right)_{2} \text { (tet }\right)_{6}\right] \cdot$ nSolv (3 and $\mathbf{4}$, respectively) were isolated. $^{21}$ Their XRPD structural analysis showed that these two isomorphous species ${ }^{22}$ are constituted by octanuclear Ni(II) hydroxo clusters linked by tetradentate $\mu_{4}$-pbp and $\mu_{4}$-tet ligands in a complex $\mathrm{Ni}_{8}\left(\mu_{4}-\mathrm{X}\right)_{6}\left(\mu_{4}-\mathrm{L}\right)_{6}$ polyhedron of rigorous cubic symmetry $(\mathrm{X}=$ $\mathrm{OH}^{-}$or $\mathrm{H}_{2} \mathrm{O} ; \mathrm{L}=\mathrm{pbp}$ or tet). Figure 1 shows the local stereochemistry of the octametallic node, which closely resembles that of the recently reported $\left[\mathrm{Ni}_{8}(\mathrm{OH})_{6}\left(\mu_{2} \text {-pyrazolate }\right)_{12}\right]^{2-}$ anion. ${ }^{23}$ Similarly to the latter species, each $\mathrm{Ni}(\mathrm{II})$ ion in $\mathbf{3}$ and $\mathbf{4}$ is hexacoordinated in a $f a c-\mathrm{NiN}_{3} \mathrm{O}_{3}$ fashion and shows intermetallic nonbonding distances close to $3.0 \AA(2.96-3.00 \AA$ in ref 23$)$.

In 3 and 4, the presence of long and rigid bis(exobidentate) spacers possessing pyrazolato moieties at both ends induces the formation of a $f c c$ packing of the $\left[\mathrm{Ni}_{8}\left(\mu_{4}-\mathrm{X}\right)_{6}\right]^{12+}$ clusters, each linked to 12 symmetry-related nodes by the $\mu_{4}-\mathrm{L}^{2-}$ ligands and maintained more than $17 \AA$ apart (see Figure 1). As recently encountered in $\mathrm{Zr}_{6} \mathrm{O}_{4}(\mathrm{OH})_{4}\left(\mathrm{~L}^{*}\right)_{6}$ ( $\mathrm{L}^{*}=$ linear polyphenylendicarboxylates $){ }^{2}$ this favorable topology and coordination geometry result in highly porous 3D frameworks: indeed, upon elimination of the residual solvents from the as-prepared samples, they possess accessible octahedral cavities ( $\mathrm{ca}$. $72 \%$ void volume in $\mathbf{3}, \mathrm{ca}$. $70 \%$ in 4) and, consequently, very low crystal density (down to less than $0.50 \mathrm{~g} \mathrm{~cm}^{-3}$ ). Therefore, these materials are ideal candidates for gas sorption investigations. As a matter of fact, they show high $\mathrm{N}_{2}$ sorption capacities, with Langmuir surface areas peaking well above $1700 \mathrm{~m}^{2} \mathrm{~g}^{-1}$. Notably, the occurrence and stability of these selfassembled octanuclear Ni(II) SBUs in the presence of different pyrazolato-based ligands can be fruitfully used in constructing finely tuned, isoreticular porous coordination polymers with even longer, or differently functionalized, spacers.

A special comment is deserved by the still ambiguous formulation set above for compounds $\mathbf{3}$ and $\mathbf{4}$, due to structural disorder. While it is fairly obvious that solvent molecules can occupy the large voids of the structure (trapped either during direct precipitation, subsequent washing or from aerial moisture), ${ }^{25}$ it proved much more 

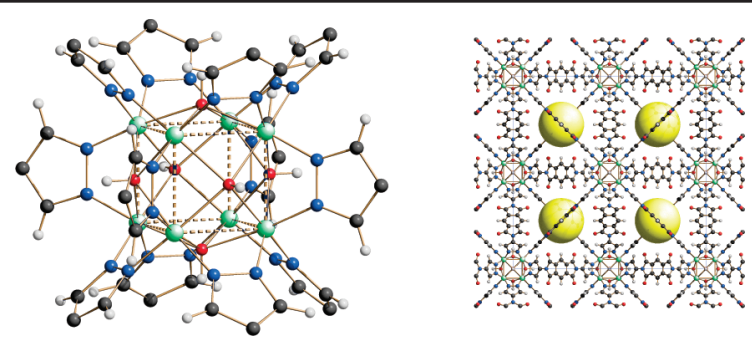

Figure 1. Left: drawing of the $\mathrm{Ni}_{8}\left(\mu_{4}-\mathrm{X}\right)_{6}\left(\mu_{4}-\mathrm{L}\right)_{6}$ cluster $(\mathrm{X}=$ hydroxyl or water fragments) in 3 and $\mathbf{4}$. Dashed lines are a guide to the eyes highlighting the octametallic cube. For simplicity, all X ligands are idealized as hydroxyl groups. Right: drawing of the crystal packing in 4, showing, with yellow solid spheres, the location (neither the sizes nor the shapes) of the cavities obtained upon mild evacuation of the solid, accounting for $\sim 70 \%$ of the crystal volume.

difficult to assess the real nature of the $\mathrm{X}$ ligands, which we model as a 2:1 ratio of $\mathrm{OH}^{-}$and $\mathrm{H}_{2} \mathrm{O}$ moieties. As a matter of fact, species 3 and 4 contain octanuclear clusters similar to those found in $\left[\mathrm{Ni}_{8}(\mathrm{OH})_{4}\left(\mathrm{H}_{2} \mathrm{O}\right)_{2}\left(\mathrm{C}_{5} \mathrm{H}_{9} \mathrm{O}_{2}\right)_{12}\right],{ }^{26}$ where two of the six $\mu_{4}-\mathrm{O}$ atoms were found to belong to water, rather than hydroxo, ligands, statistically distributed on the surface of the $\mathrm{Ni}_{8}$ cube. Aiming at the full comprehension of the nature of $\mathbf{3}$ and $\mathbf{4}$, we have chosen the latter as a representative example to perform a number of complex spectroscopic analyses. The DRS-UV-vis spectrum of 4 (blue curve in Figure 2a) shows electronic transitions associated with the organic linker 2 (three strong bands peaking at 34500 , 29500 , and $22300 \mathrm{~cm}^{-1}$, gray curve) and two weaker $d-d$ transitions for pseudo octahedral Ni(II) ions (15 900, $\left.10200 \mathrm{~cm}^{-1}\right)$.

The latter are perturbed upon water removal (Figure 2a) testifying a distortion of the Ni(II) coordination sphere. The IR spectra of the as-prepared sample and those obtained upon its activation at increasing temperatures, up to $453 \mathrm{~K}$, are shown in Figure $2 \mathrm{~b}$. Beyond the expected bands due to the linker (lying in the $3160-2850$ and $1790-500 \mathrm{~cm}^{-1}$ ranges; see SI for the latter), progressive elimination of water is observed with a sharpening of the absorption band at $3593 \mathrm{~cm}^{-1}$, attributed to the bridging $\mathrm{OH}$ groups located on the faces of $\mathrm{Ni}_{8}$ units. Worthy of note, this band lies at a significantly lower frequency than that observed for the hydroxyl groups in Ni-phosphonates, ${ }^{27}$ likely because of the unusual $\mu_{4}$-bridging mode of the hydroxyl moieties in 4 . Notably, the persistence of a band centered at $3370 \mathrm{~cm}^{-1}$, even after prolonged outgassing at $453 \mathrm{~K}$, can only be explained by considering the presence of structural water molecules that cannot be removed without compromising the MOF structure. These assignments are confirmed by IR spectroscopy, namely $\mathrm{D}_{2} \mathrm{O}$-induced proton exchange and (low temperature) framework interaction with $\mathrm{CO}$ (see SI for further details).

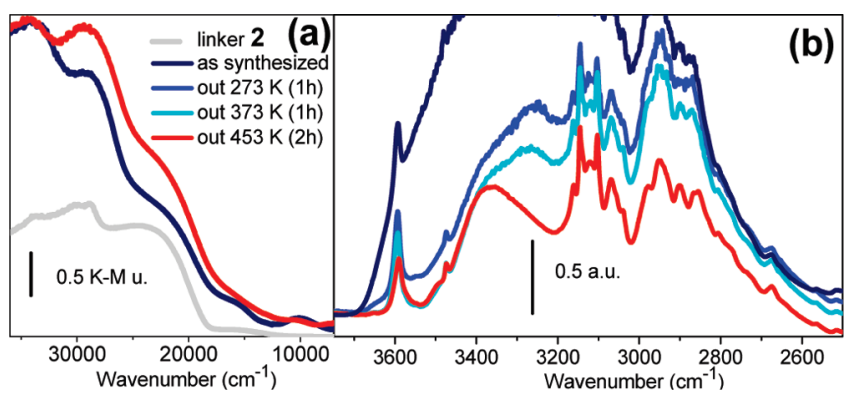

Figure 2. Effect of successive outgassing (see legend) on UV-vis (a) and IR spectra (b) of $\mathbf{4}$. Also the spectrum of $\mathbf{2}$ is reported in (a). K-M u. = Kubelka-Munk units; a.u. $=$ absorbance units.
The XANES spectrum of $\mathbf{4}$ (Figure 3a) is very similar to that observed for the Ni-CPO-27 MOF, ${ }^{28}$ confirming that in 4 (pseudo)octahedral $\mathrm{Ni}(\mathrm{II})$ ions are present, discarding, at the same time, the presence of mixed-valence $\mathrm{Ni}(\mathrm{II}) / \mathrm{Ni}$ (III) clusters. More in detail, three main transitions can be observed: a very weak $1 s \rightarrow 3 d$ dipoleforbidden electronic transition at $8333.3 \mathrm{eV}$; a strong $1 s \rightarrow 4 p$ dipoleallowed one near $8343 \mathrm{eV}$ (scarcely visible because too close to the edge jump); and a white line at $8349.5 \mathrm{eV}$ (first resonance after the edge). Worthy of note, the higher intensity of the $1 s \rightarrow 3 d$ transition observed in $\mathbf{4}$ with respect to that observed in the $\mathrm{Ni}$ CPO-27 MOF reflects a higher distortion from a perfect local $O_{h}$ symmetry: in 4 the $\mathrm{NiN}_{3} \mathrm{O}_{3}$ chromophore is present, while in $\mathrm{Ni}$ CPO-27 six (chemically unequivalent) oxygen atoms are bound to $\mathrm{Ni}(\mathrm{II})$; see SI for direct comparison.

As was the case for other MOF systems, ${ }^{2,28}$ notwithstanding the knowledge of the structure from XRPD, EXAFS data interpretation was not straightforward (see SI). Indeed, several single and multiple scattering (SS and MS) paths contribute to the overall amplitude. Contributions of the SS paths N1 (joint with O1), N2, Ni1, and $\mathrm{Ni}$, as can be singled out in Figure $3 \mathrm{c}$, are highlighted as colored traces in Figure $3 b$ in k-space. The final results of the structural refinement are shown in Table 1: the experimental geometrical parameters derived from our combined EXAFS and XRPD data analysis confirm the powder X-ray structure presented above, ruling out the presence of extraframework nickel-containing cations, ${ }^{28}$ balancing metallic nodes of a much simpler $\left[\mathrm{Ni}_{8}(\mathrm{OH})_{6}\left(\mu_{4}-\mathrm{L}\right)_{6}\right]^{2-}$ formulation.

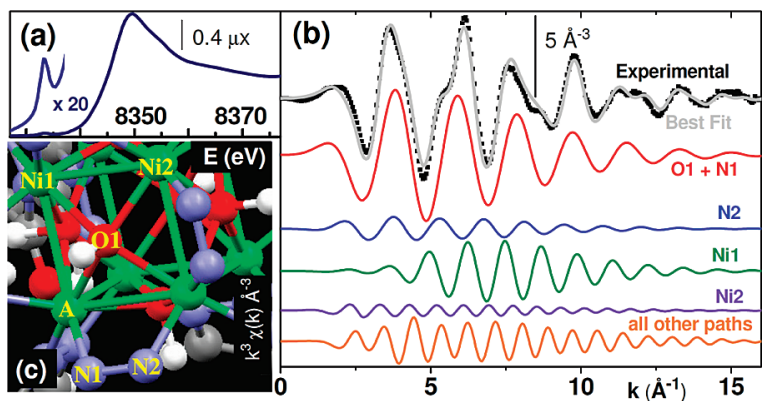

Figure 3. XANES spectrum for species 4 (a). Results of the EXAFS analysis for species $\mathbf{4}$ in k-space (b), reporting the most important SS contributions defined from the cluster shown in (c), where $\mathrm{A}=$ adsorber.

The possible presence of other extraframework cationic moieties was thoroughly tested and coherently discarded, by coupling elemental analyses as well as chemical and unconventional spectroscopic evidence (see SI): the presence of protonated cations of the $\mathrm{H}_{3} \mathrm{~L}^{+}$type could be ruled out through vibrational spectroscopy, elemental analysis, and in view of the basic environment in which the syntheses were performed. We are thus left with the final formulation of species 3 and $\mathbf{4}$ as $\left[\mathrm{Ni}_{8}(\mathrm{OH})_{4}\left(\mathrm{OH}_{2}\right)_{2}\left(\mu_{4}-\mathrm{L}\right)_{6}\right] \cdot n \mathrm{H}_{2} \mathrm{O}$, eventually clearing out the ambiguity put forward in the previous text.

The thermal stability of these coordination polymers has been investigated by DSC/TG and, particularly, by thermodiffractometric analyses. As shown in Figure 4, compound $\mathbf{4}$ is stable from rt (blue trace) up to $410{ }^{\circ} \mathrm{C}$, where decomposition begins. In this temperature range, variable temperature $\mathrm{X}$-ray powder diffraction data indicate a substantial constancy of the crystal structure, with only marginal changes of some low-angle peak intensity, due to water elimination. This process is reversible: in open air, moisture is readsorbed in a few hours. 
Table 1. Summary of EXAFS 30 and XRPD Results; Esd's in Parentheses

\begin{tabular}{llll}
\hline \multicolumn{1}{c}{ Parameter } & EXAFS (4) & \multicolumn{1}{c}{ XRPD (3) } & \multicolumn{1}{c}{ XRPD (4) } \\
\hline$R$-factor & 0.011 & $a$ & $\mathrm{a}$ \\
$\Delta E_{0}, \mathrm{eV}$ & $-4.1(5)$ & - & - \\
$S_{0}{ }^{2}$ & $0.92(4)$ & - & - \\
$\left\langle R_{\mathrm{O} 1, \mathrm{~N} 1}\right\rangle, \AA$ & $2.04(1)$ & $2.09-2.15$ & $2.01-2.08$ \\
$\sigma^{2}(\mathrm{O} 1, \mathrm{~N} 1), \AA^{2}$ & $0.0087(5)$ & - & - \\
$R_{\mathrm{N} 2}, \AA$ & $2.77(2)$ & 2.89 & 2.88 \\
$\sigma^{2}(\mathrm{~N} 2), \AA^{2}$ & $0.010(2)$ & - & - \\
$R_{\mathrm{Ni1}}, \AA$ & $2.96(1)$ & 2.92 & 2.83 \\
$\sigma^{2}(\mathrm{Ni} 1), \AA^{2}$ & $0.011(1)$ & - & - \\
$R_{\mathrm{Ni2}}, \AA$ & $4.12(3)$ & 4.13 & 4.08 \\
$\sigma^{2}(\mathrm{Ni} 2), \AA^{2}$ & $0.010(3)$ & - & - \\
$\alpha($ all other paths $)$ & $-0.03(3)$ & - & - \\
$\sigma^{2}$ (all other paths), $\AA^{2}$ & $0.007(1)$ & - & - \\
\hline
\end{tabular}

${ }^{a}$ See crystal data in ref 22.

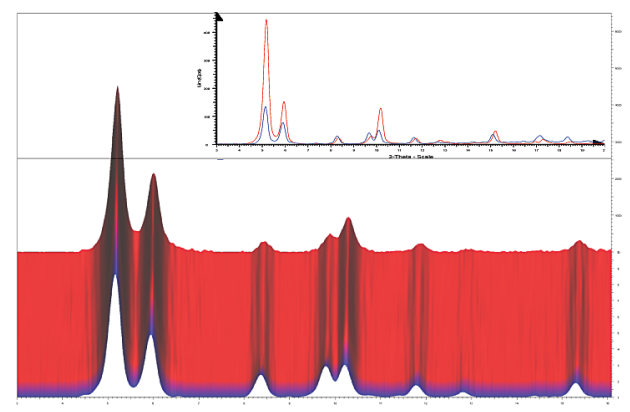

Figure 4. Thermodiffractogram of species $\mathbf{4}$, highlighting the substantial constancy of its XRPD pattern, when heated, in air, from rt (blue trace) to $410{ }^{\circ} \mathrm{C}$. The upper insert shows the relative changes of peak intensities due to extraframework water elimination.

In summary, state-of-the-art structural powder diffraction techniques (which have recently increased the basket of structural tools in the structural chemist's hands, ${ }^{29}$ well beyond the traditional methods of qualitative and quantitative analyses) were coupled with $\mathrm{X}$-ray absorption techniques and spectroscopic measurements, allowing the detection and confirmation of relevant stereochemical features and, above all, the determination of the correct, but elusive, stoichiometry of these $\left[\mathrm{Ni}_{8}(\mathrm{OH})_{4}\left(\mathrm{OH}_{2}\right)_{2}\left(\mu_{4}-\mathrm{L}\right)_{6}\right] \cdot n \mathrm{H}_{2} \mathrm{O}$ porous coordination polymers.

Acknowledgment. Fondazione CARIPLO (Project No. 20075117) is heartily acknowledged for funding. Mr. Iacopo Galli, for helping in the syntheses, and Dr. Damiano Monticelli, for helping in ICP-MS analyses, are also acknowledged. XANES and EXAFS spectra were collected at BM26A at ESRF. ${ }^{30}$

Supporting Information Available: Details on the synthesis, spectroscopy, crystallographic analysis (CIF files and Rietveld refinement plots) of species 1-5; TG and DSC plots for species 1-4. Details on the XANES and EXAFS data acquisition and analysis. EXAFS fit in R-space. Details on the IR and DRS-UV-vis analyses; IR spectra down to $50 \mathrm{~cm}^{-1}$. This material is available free of charge via the Internet at http://pubs.acs.org.

\section{References}

(1) Batten, S.; Neville, S. N.; Rurner, D.R. Coordination Polymers: Design, Analysis and Application; RSC Publishing: 2009, Cambridge, U.K.

(2) Cavka, J. H.; Jakobsen, S.; Olsbye, U.; Guillou, N.; Lamberti, C.; Bordiga, S.; Lillerud, K. P. J. Am. Chem. Soc. 2008, 130, 13850-13851.

(3) Britt, D.; Tranchemontagne, D. J.; Yaghi, O. M. Proc. Natl. Acad. Sci. U.S.A. 2008, 105, 11623-11627, and references therein.

(4) Galli, S.; Masciocchi, N.; Colombo, V.; Maspero, A.; Palmisano, G.; LopezGarzon, F. J.; Domingo-García, M.; Fernandez-Morales, I.; Barea, E.;
Navarro, J. A. R. Chem. Mater. 2010, 22, 1664-1672, and references therein.

(5) Czaja, A. U.; Trukhan, N.; Müller, U. Chem. Soc. Rev. 2009, 38, 12841293.

(6) Long, J. R.; Yaghi, O. M. Chem. Soc. Rev. 2009, 38, 1213-1214.

(7) Tranchemontagne, D. J.; Mendoza-Cortés, J. L.; O’Keeffe, M.; Yaghi, O. M. Chem. Soc. Rev. 2009, 38, 1257-1283.

(8) Eddaoudi, M.; Kim, J.; Rosi, N.; Vodak, D.; Wachter, J.; O'Keeffe, M.; Yaghi, O. M. Science 2002, 295, 469-472.

(9) Eddaoudi, M.; Moler, D.; Li, H.; Reineke, T. M.; O'Keeffe, M.; Yaghi, O. M. Acc. Chem. Res. 2001, 34, 319-330, and references therein.

(10) Férey, G.; Serre, C. Chem. Soc. Rev. 2009, 38, 1380-1399, and references therein.

(11) Choi, H. J.; Dinca, M.; Long, J. R. J. Am. Chem. Soc. 2008, 130, 78487850 .

(12) Masciocchi, N.; Galli, S.; Sironi, A. Comm. Inorg. Chem. 2005, 26, 1-37.

(13) Masciocchi, N.; Corradi, E.; Moret, M.; Ardizzoia, G. A.; Maspero, A.; La Monica, G.; Sironi, A. Inorg. Chem. 1997, 36, 5648-5650.

(14) Masciocchi, N.; Moret, M.; Cairati, P.; Sironi, A.; Ardizzoia, G. A.; La Monica, G. J. Am. Chem. Soc. 1994, 116, 7668-7676.

(15) Ardizzoia, G. A.; La Monica, G.; Masciocchi, N.; Maspero, A.; Sironi, A. Angew. Chem., Int. Ed. 1998, 37, 3366-3369.

(16) Galli, S.; Masciocchi, N.; Tagliabue, G.; Sironi, A.; Navarro, J. A. R.; Salas, J. M.; Mendez-Liñan, L.; Domingo, M.; Perez-Mendoza, M.; Barea, E. Chem.-Eur. J. 2008, 14, 9890-9901, and references therein.

(17) Maspero, A.; Galli, S.; Masciocchi, N.; Palmisano, G. Chem. Lett. 2008, $37,956-957$.

(18) He, X.; An, B.-L.; Li, M.-X. Acta Crystallogr. 2008, E64-040.

(19) Vilsmeier, A.; Haack, A. Ber. 1927, 60, 119.

(20) Crystal data for $\mathbf{1}: \mathrm{C}_{18} \mathrm{H}_{14} \mathrm{~N}_{4}, \mathrm{fw}=286.34 \mathrm{~g} \mathrm{~mol}^{-1}$, monoclinic, $P 2_{1} / c, a$ $=16.042(2) \AA, b=5.5181(6) \AA, c=7.8621(7) \AA, \beta=93.96(1)^{\circ}, V=$ 694.3(1) А $, Z=2, \rho=1.370 \mathrm{~g} \mathrm{~cm}^{-3}, \mu(\mathrm{Cu} \mathrm{K \alpha})=67.1 \mathrm{~mm}^{-1}, R_{\mathrm{p}}, R_{\mathrm{wp}}$, and $R_{\mathrm{Bragg}}=0.035,0.048,0.015$, respectively, for 3501 data collected in the 5. $0^{\circ}-75.0^{\circ} 2 \Theta$ range. Crystal data for $2: \mathrm{C}_{16} \mathrm{H}_{8} \mathrm{~N}_{6} \mathrm{O}_{4}$, fw $348.28 \mathrm{~g}$ $\mathrm{mol}^{-1}$, monoclinic, $P 2_{1} / c, a=5.2503(4) \AA, b=5.3608(3) \AA, c=24.376(2)$ $\AA, \beta=90.480(4)^{\circ}, V=686.0(1) \AA^{3}, Z=2, \rho=1.686 \mathrm{~g} \mathrm{~cm}^{-3}, \mu(\mathrm{Cu} \mathrm{K \alpha})$ $=108.3 \mathrm{~mm}^{-1}, R_{\mathrm{p}}, R_{\mathrm{wp}}$, and $R_{\mathrm{Bragg}}=0.075,0.104,0.058$, respectively, for 5001 data collected in the $5.0^{\circ}-105.0^{\circ} 2 \Theta$ range.

(21) If, instead, $\mathrm{NiCl}_{2} \cdot 6 \mathrm{H}_{2} \mathrm{O}$ is reacted with $\mathrm{H}_{2}$ tet, a different species, $\left[\mathrm{NiCl}_{2}\left(\mathrm{H}_{2} \mathrm{tet}\right)\right](\mathbf{5})$, is formed, structurally characterized by XRPD analysis as containing 2D layers built upon pseudooctahedral trans $-\mathrm{NiCl}_{4} \mathrm{~N}_{2}$ chromophores linked in infinite $\mathrm{NiCl}_{2}$ ribbons. Crystal data for 5: $\mathrm{C}_{16} \mathrm{H}_{8} \mathrm{Cl}_{2} \mathrm{~N}_{6} \mathrm{NiO}_{4}$, fw $=477.88 \mathrm{~g} \mathrm{~mol}^{-1}$, triclinic, $P \overline{1}, a=6.315(1) \AA \mathrm{A}, b=$ $3.620(1) \AA, c=18.443(3) \AA, \alpha=94.85(3)^{\circ}, \beta=109.93(1)^{\circ}, \gamma=89.25(3)^{\circ}$, $V=394.5(2) \AA^{3}, Z=1, \rho=2.012 \mathrm{~g} \mathrm{~cm}^{-3}, \mu(\mathrm{Cu} \mathrm{K} \alpha)=531.9 \mathrm{~mm}^{-1}, R_{\mathrm{p}}$, $R_{\mathrm{wp}}$ and $R_{\mathrm{B} \text { ag }}=0.025,0.036,0.023$, respectively, for 3525 data collected in the $4.5^{\circ}-75.0^{\circ} 2 \Theta$ range. Differently, the reaction of $\mathrm{H}_{2} \mathrm{pbp}$ with $\mathrm{NiCl}_{2} \cdot 6 \mathrm{H}_{2} \mathrm{O}$ affords 4, i.e., the same product obtained with nickel acetate.

(22) Crystal data for 3, $\left[\mathrm{Ni}_{8}(\mathrm{OH})_{4}\left(\mathrm{OH}_{2}\right)_{2}\left(\mu_{4}-\mathrm{pbp}\right)_{6}\right], \mathrm{C}_{108} \mathrm{H}_{80} \mathrm{~N}_{24} \mathrm{Ni}_{8} \mathrm{O}_{6}, \mathrm{fw}=$ $2279.53 \mathrm{~g} \mathrm{~mol}^{-1}$, cubic, $F m \overline{3} m, a=31.358(3) \AA, V=30836(9) \AA^{3}, Z=$ $4, \rho=0.49 \mathrm{~g} \mathrm{~cm}^{-3}, \mu(\mathrm{Cu} \mathrm{K \alpha})=69.8 \mathrm{~mm}^{-1}, R_{\mathrm{p}}, R_{\mathrm{wp}}$, and $R_{\text {Bragg }}=0.007$, $0.012,0.008$, for 3626 data collected in the $7.5^{\circ}-80.0^{\circ} 2 \Theta$ range. Crystal data for 4: $\left[\mathrm{Ni}_{8}(\mathrm{OH})_{4}\left(\mathrm{OH}_{2}\right)_{2}\left(\mu_{4} \text {-tet }\right)_{6}\right] \cdot 6 \mathrm{H}_{2} \mathrm{O}, \mathrm{C}_{96} \mathrm{H}_{56} \mathrm{~N}_{36} \mathrm{Ni}_{8} \mathrm{O}_{36}, \mathrm{fw}=2759.27$ $\mathrm{g} \mathrm{mol}^{-1}$, cubic, $F m 3 m, a=30.5845(2) \AA, V=28610(6) \AA^{3}, Z=4, \rho=$ $0.64 \mathrm{~g} \mathrm{~cm}^{-3}, \mu(\mathrm{Cu} \mathrm{K \alpha})=89.4 \mathrm{~mm}^{-1}, R_{\mathrm{p}}, R_{\mathrm{wp}}$, and $R_{\text {Bragg }}=0.030,0.054$, 0.054 , for 4876 data collected in the $7.5^{\circ}-105.0^{\circ} 2 \Theta$ range.

(23) Xu, J.-Y.; Qiao, X.; Song, H.-B.; Yan, S. P.; Liao, D.-Z.; Gao, S.; Journaux, Y.; Cano, J. Chem. Commun. 2008, 6414-6416.

(24) The presence of (disordered) solvent is witnessed by the fact that framework atoms alone did not model the whole X-ray scattered intensity. The lessthan-ideal quality of the XRPD traces hampered solvent modeling.

(25) Ovcharenko, V.; Fursova, E.; Romanenko, G.; Eremenko, I.; Tretyakov, E. Ikorskii, V. Inorg. Chem. 2006, 45, 5338-5350.

(26) Miller, S. R.; Pearce, G. M.; Wright, P. A.; Bonino, F.; Chavan, S.; Bordiga, S.; Margiolaki, I.; Guillou, N.; Férey, G.; Bourrelly, S.; Llewellyn, P. L. J. Am. Chem. Soc. 2008, 130, 15967-15981.

(27) (a) Bonino, F.; Chavan, S.; Vitillo, J. G.; Groppo, E.; Agostini, G.; Lamberti, C.; Dietzel, P. D. C.; Prestipino, C.; Bordiga, S. Chem. Mater. 2008, 20, 4957-4968. (b) Chavan, S.; Vitillo, J. G.; Groppo, E.; Bonino, F.; Lamberti, C.; Dietzel, P. D. C.; Bordiga, S. J. Phys. Chem. C 2009, 113, 3292-3299. (c) Chavan, S.; Bonino, F.; Vitillo, J. G.; Groppo, E.; Lamberti, C.; Dietzel, P. D. C.; Zecchina, A.; Bordiga, S. Phys. Chem. Chem. Phys. 2009, 11, 9811-9822.

(28) Hafizovic, J.; Bjorgen, M.; Olsbye, U.; Dietzel, P. D. C.; Bordiga, S.; Prestipino, C.; Lamberti, C.; Lillerud, K. P. J. Am. Chem. Soc. 2007, 129 , $3612-3620$.

(29) David, W. I. F., Shankland, K., McCusker, L. B.; Bärlocher, Ch., Eds.; Structure determination from powder diffraction data; Oxford University Press: 2006, Oxford, U.K.

(30) The fit was performed in R-space in the 1.0-4.5 $\AA$ range over $k^{3}$-weighted FT of the $\chi(k)$ functions performed in the $2.0-16.0 \AA^{-1}$ interval. A single $\Delta E_{0}$ and a single $S_{0}{ }^{2}$ have been optimized for all SS and MS paths. The $\mathrm{Ni}-\mathrm{O}$ and $\mathrm{Ni}-\mathrm{Ni}$ (first and second neighbor) SS paths have been modeled with their own path length and Debye-Waller factors, while a unique $\sigma^{2}$ and a unique path length parameter $\alpha$, common to all other SS and MS paths, have been optimized.

(31) Nikitenko, S.; Beale, A. M.; van der Eerden, A. M. J.; Jacques, S. D. M.; Leynaud, O.; O'Brien, M. G.; Detollenaere, D.; Kaptein, R.; Weckhuysen, B. M.; Bras, W. J. Synchrotron Radiat. 2008, 15, 632-640.

JA102862J 